\section{Funding assured for India's international biotechnology centre ...}

Sir - We are writing to you in our capacity as president of the board of governors of the International Centre for Genetic Engineering and Biotechnology (ICGEB), and director general of the ICGEB, respectively. We are utterly surprised by the content and the tone of your Editorial and News item about this centre (Nature 408, $121 \& 127 ; 2000)$.

Last November a meeting of the board of governors, representing the 43 countries involved, very positively appraised the activity of both the Italian and the Indian components of the ICGEB and confirmed the board's total confidence in the ICGEB management, including Professor V. S. Chauhan, director of the New Delhi component. This positive evaluation was also based on a glowing report by the ICGEB council of scientific advisers an independent body of 15 distinguished scientists.

The board was totally satisfied that the turnover of personnel is at a normal level for a research institution and that the hiring of all personnel is done in full transparency, without any external pressure, political or otherwise, but purely on professional grounds. Furthermore, the morale of the scientists working at the ICGEB is quite good, as witnessed by the accompanying letter that has been sent to you by the New Delhi scientific staff.

Their morale has been further heightened by the outcome of the board's meeting: the government of Italy has just passed a law to triple its annual contribution to the centre (hardly a sign of "donor fatigue") and the government of India has promised to do likewise. All the other governors present at the meeting have assured that their countries will fulfil their financial commitments to the ICGEB. Furthermore, grants to ICGEB scientists from several major international foundations and agencies are steadily on the increase.

Adolfo R. Taylhardat, Arturo Falaschi International Centre for Genetic Engineering and Biotechnology, Padriciano 99, 34012 Trieste, Italy

\section{... and senior staff say there's no problem}

Sir - The description of the working conditions and scientific atmosphere at the International Centre for Genetic Engineering and Biotechnology (ICGEB), in your News report (Nature 408, 127;
2000) comes as a surprise to us. We represent $90 \%$ of the senior investigators working at the ICGEB, New Delhi, and we do not agree that there have been "deteriorating working conditions" at our centre. If Nature had solicited views from a wide range of scientists working at the ICGEB you would have got a completely different view of the working conditions and atmosphere here.

The healthy scientific atmosphere at the ICGEB, New Delhi, is reflected in the scientific output of the centre. In addition to a growing list of publications in international scientific journals, ICGEB investigators have been successful in attracting grant support from a wide range of international funding agencies including the Wellcome Trust, Howard Hughes Medical Institute, the World Health Organization, the European Commission, the Rockefeller Foundation, the (US) National Institutes of Health and the Human Frontiers Science Program in recent years.

Moreover, the activities of the ICGEB are reviewed annually by an independent council of scientific advisers (CSA), which includes two Nobel laureates. The two CSA members quoted by your correspondent had only positive things to say about the scientific work of the ICGEB, New Delhi. We believe that the quality of our scientific research is a direct reflection of the healthy working atmosphere prevailing here.

\section{S. K. Sopory}

Other signatories to this letter:

V. Siva Reddy, Raj Bhatnagar, Sunil Kumar Mukherjee, Nirupama Bhatnagar, Kanury V. S. Rao, Suresh Nair,

N. Tuteja, Neeti Sanan Mishra, Nirupam Roy Choudhury, M. K. Reddy, Raman Rajagopal, Krishnamurthy Natarajan, Suman Dhawan, Chetan Chitnis, Pawan Malhotra,

Sadhu Leelaavathi, Ashima Kushwaha, Sunil K. Lal, Deepak Sehgal, S. Swaminathan, N. Khanna, Shahid Jameel, Anand Ranganathan

International Centre for Genetic Engineering and Biotechnology, Aruna Asaf Ali Marg, 110067 New Delhi, India

\section{Doing our best for returners to Spain}

Sir - The letter signed by Pau Ferrer et al. (Nature 407, 941; 2000) accurately describes the severe problems that young researchers face in rejoining the Spanish research system after several years abroad. Although I fully share their frustration and concern, the letter contains some statements that need clarification.

The writers mention a "lecturing policy document" produced by the Universitat Autònoma de Barcelona (UAB). Our policy has been to create transitory five-year posts for people who already had a very precarious teaching contract with the $\mathrm{UAB}$. The posts are occupied by $\mathrm{PhDs}$, some of them with research experience abroad. Such positions are equivalent to teaching assistantships in the US academic system (not to assistant professorships, as the letter says). After the fifth year, there will be tenured positions by public and open competition, and any citizen with a $\mathrm{PhD}$ is welcome to apply.

Academic rights within the UAB were established through our democratic bylaws 15 years ago; they are our 'constitution'. Unfortunately we could not predict, so long ago, that the Ministry of Education would select and fund reincorporated scientists. This is why they are not now represented on the university's elected body. This issue, however, may be revised in the near future to allow for this and other unforeseeable situations. In other important aspects of academic life, people in these situations face no discrimination, to the best of my knowledge.

The scientific community considers it an absolute priority for Spain to improve its efforts in R\&D. Let me emphasize that we consider young researchers with experience in good universities and prestigious research centres to be essential for the future of our society.

\section{Carme Picallo}

Universitat Autònoma de Barcelona, Edifici A-Rectorat, 08193 Bellaterra

(Barcelona), Spain

\section{Difficulty in reconciling global-warming data}

Sir-According to your Special Feature on global warming (Nature 408, 896; 2000), a scientific report issued by the US National Academy of Sciences ${ }^{1}$ concluded that the discrepancies between temperature measurements made at the surface (showing a warming trend since 1979) and from satellites (showing little if any tropospheric trend) "were now reconciled and that they pointed to a warming planet".

To be precise, the NAS panel, which included some of the severest critics of the satellite data, could not reconcile the disparity between the two trends. In fact, the disparity is opposite in direction to expectations based on climate models: climate models all predict a stronger warming trend for the mid-troposphere than for the surface.

S. Fred Singer

Science \& Environmental Policy Project,

1600 South Eads Street, Suite\#712-S, Arlington, Virginia 22202-2907, USA

1. National Research Council/National Academy of Sciences Reconciling Observations of Global Temperature Change (National Academy Press, Washington DC, 2000). 